\title{
ORGANIZAÇÃO DAS POLÍTICAS PÚBLICAS DE TURISMO NO BRASIL E NO RIO GRANDE DO NORTE
}

\section{Organization of Tourism Publics Policies in Brazil and Rio Grande do Norte State}

Prof ${ }^{a}$. Msc. Larissa da Silva Ferreira

Curso de Geografia da UERN-CAMEAM

Cx. Postal 60, CEP 59900-000, Pau dos Ferros (RN) - Brasil

Tel.: (84) 3351-2560 Ramal 215 - larissaferreira@uern.br

Prof ${ }^{a}$. Dr. Rita de Cássia da C. Gomes Bolsista Produtividade CNPQ

Programa de Pós-Graduação em Geografia da UFRN ricassia@ufrnet.br

\section{$a \cap \boldsymbol{a} a$}

\begin{abstract}
Resumo
As políticas públicas de turismo vêm ocupando, paulatinamente, espaços no âmbito do planejamento e da gestão pública no Brasil em suas diferentes escalas. Nessa perspectiva, o presente artigo objetiva fazer discussão a respeito da organização das atuais políticas públicas de turismo no Brasil, com enfoque local para o estado do Rio Grande do Norte $(\mathrm{RN})$. Constatou-se que, embora o turismo seja importante para a dinâmica econômica do país, principalmente para a região Nordeste, o Brasil ainda carece de políticas e planos locais sistematizados, tanto para o planejamento quanto para o ordenamento territorial da atividade. Verificou-se, ainda, que, embora a descentralização da gestão da atividade tenha sido uma das principais propostas políticas do Plano Nacional do Turismo 2007/2010 (PNT 2007/2010), a ausência de diretrizes nacionais, com envergadura de regular o uso e ordenamento do território, associada à fragilidade legal e institucional em escala local, fazem com que o turismo no Brasil desregule territórios e, por muitas vezes, desvirtuem projetos de nação.
\end{abstract}

Palavras-chave: Turismo, políticas públicas, gestão territorial..

\begin{abstract}
Tourism public policies have gradually been occupying spaces in the planning and public management in Brazil in its different scales. From this perspective, this article aims to discuss about the organization of current public policies for tourism in Brazil, particularly in Rio Grande do Norte (RN) state. It has been noted that, although tourism is important for the economic dynamics of the country, mainly in the Northeast, Brazil still lacks systematic policies and local plans, both for planning and the territorial management of the activity. It has also been verified that, although the decentralization of the management activity has been one of the major policy proposals of the NTP (National Tourism Plan 2007/2010), the absence of national guidelines, with a scale of regulating the use and territorial management, associated with legal and institutional fragility at the local scale, make tourism in Brazil deregulate territories, and often distort national projects.
\end{abstract}

Key words: Tourism, public policies, territorial management.

\section{Résumé}

Les politiques publiques du tourisme vient d'occuper, progressivement, les places dans le cadre de la planification et de la gestion publique au Brésil en ses différentes échelles. Dans cette perspective, cet article vise à discuter sur l'organisation des politiques publiques actuelles du tourisme au Brésil, surtout, l'État du Rio Grande do Norte (RN). Il s'est remarqué, tandis que le tourisme soit important par la dynamique économique du pays, essentiellement pour le Nord-est, le Brésil manque encore des politiques et des plans systématiques locaux, tant pour la planification que l'aménagement territorial de l'activité. Il s'est vérifié encore, bien que la décentralisation de la gestion d'activité a été une des principales propositions politiques du PNT ( Plan National du Tourisme 2007/2010), l'absence de directives nationales, dont l'objectif est régulière l'utilisation et l'aménagement du terroire, associe à la fragilité légale et institutionnelle à l'échelle locale, en faisant du tourisme au Brésil dérégle les territoires, en déformant, quelques fois, les projets nationaux.

Mots clés: Tourisme, politiques publiques, gestion territoriale.

$$
\text { åa a }
$$




\section{INTRODUÇÃO}

O turismo, no contexto mundial contemporâneo, é uma das mais importantes atividades econômicas, gerando, além de renda, intercâmbios de pessoas e de culturas. Deixa de ser compreendido como um simples fenômeno (pontual e singular) para fazer parte da realidade cotidiana. Tornou-se prática social possibilitada pela globalização.

Aliado ao conhecimento de expansão da atividade, enquanto produto econômico, o turismo tem sido alvo de debate pelos atuais estudos no que se refere à necessidade de seu ordenamento e gestão territorial, haja vista a capacidade da atividade de organizar sociedades e de condicionar tendências e ocupações territoriais. Nessa medida, questiona-se o papel cabível ao setor no (re)ordenamento dos territórios, para que se estabeleçam normas e diretrizes de sua regulação e ordenamento territoriais.

Ensaios realizados por Becker (1996) discutem tal necessidade, afirmando que o turismo no Brasil é espacializado por dois padrões de desenvolvimento: o padrão desenvolvimentista, no sentido de crescimento a qualquer preço, rápido, desenfreado, e também uma tentativa de se ordenar e disciplinar o uso do território. O papel da União é fundamental no sentido da regulação. Segundo a autora, ela deve: regular a competição entre os estados; estabelecer as regras do jogo; disciplinar o uso do solo; controlar as parcerias estabelecendo limites e estímulos para a prevenção de problemas territoriais genuinamente oriundos da atividade turística, como a fragmentação do território, desigualdades socioespaciais, especulação do setor imobiliário e demais formas de diferenciação espacial.

Será, pois, com essa compreensão de responsabilidade do Estado para com o seu território que este artigo objetiva mostrar a organização das políticas públicas de turismo no Brasil e seus direcionamentos de fazer do turismo um elemento agregador do espaço e um instrumento de coesão territorial.

\section{ORGANIZAÇÃO DAS POLÍTICAS PÚBLICAS DE TURISMO NO BRASIL: A ESCALA NACIONAL}

O Brasil vem passando pela latente necessidade de se planejar o turismo de uma maneira integrada, em decorrência da expansão da atividade em diversas partes do território nacional, bem como do aumento de sua importância tanto para o fomento de economias locais quanto pelo fato da atividade já ter se tornado um vetor ativo de mudanças socioespaciais. Tal necessidade é resultado da posição marginal a que o planejamento do turismo é relegado no âmbito da gestão pública, apesar do reconhecimento da atividade como segmento gerador de emprego e renda. Becker (2008), fazendo um resgate histórico do planejamento do turismo no Brasil, afirma que, em 1958, no governo de Juscelino Kubitschek, com projetos de integração nacional aliados ao mercado de automotivos e à construção de estradas, houve uma política para formação de uma classe média proprietária de carros particulares de passeio. Becker (2008, p. 05) afirma que foi "a gestação da classe média do Fusca" que viabilizou uma ampliação da circulação mercantil, passando a desenvolver os mercados turísticos brasileiros.

Porém, diversos estudos, dentre eles os realizados por Bonald (1978), apontam que foi o ano de 1966 o grande marco do planejamento do turismo no Brasil, a partir da criação da Empresa Brasileira de Turismo, atualmente denominada Instituto Brasileiro de Turismo (EMBRATUR), uma autarquia nacional com o objetivo de propagação e expansão comercial do turismo. Segundo o referido autor, nesse período (1960-1970), o turismo ainda era visto como mero componente nas políticas de desenvolvimento regional. Ele foi inserido no II Plano Nacional de Desenvolvimento Econômico e Social (PND, já na década de 1970) como uma nova indústria a ser fomentada. De acordo com o II PND, o turismo passou a ser desenvolvido como uma "estratégia regional", pensada preponderantemente para o litoral brasileiro, passando a compor, a partir de então, os principais programas setoriais do plano, que envolviam, por exemplo, a pecuária de corte, extração e industrialização 
de madeira, mineração e indústrias eletrolíticas, lavouras selecionadas de caráter comercial e base agronômica assegurada, além da pesca empresarial. (BRASIL, II PND, 1974)

O turismo começa, então, a ser visto como uma atividade econômica capaz de gerar lucros e como um novo programa setorial. As principais preocupações do II PND em relação ao setor eram voltadas ao disciplinamento do processo de urbanização, à preservação das belezas e paisagens naturais, à preservação do patrimônio histórico-cultural de cidades serranas e, principalmente, à preservação das litorâneas para o desenvolvimento e a subsistência do turismo de lazer . A partir da década anteriormente mencionada (1970), o planejamento do turismo começa a tomar um caráter regionalizado, com programas específicos para determinadas localidades. Em consequência desses programas, planos específicos de gestão territorial do turismo foram elaborados, como, por exemplo, o Planejamento Turístico da Orla Marítima da Bahia, o Programa de Promoção e Turismo no Ceará, o Plano de Turismo de João Pessoa e o I Plano Integrado de Desenvolvimento Turístico de Pernambuco, os quais passaram a ser desenvolvidos a partir do ano de 1975, com o objetivo de começar a regulamentar, zonear e ordenar o uso do solo para o turismo.

Contudo, como o enfoque deste artigo é compreender as políticas públicas de turismo a partir do ordenamento e gestão territoriais dados a essa atividade, lembramos, com base em Pujadas \& Font (1998), que o OT pode ter um caráter setorial. Todavia, o turismo não pode estar desconectado de outros setores e atividades e, nesta perspectiva, Estaba (1999) afirma que o ordenamento territorial visa à sistematização do desenvolvimento no espaço geográfico a partir da ponderação de interesses adversos.

Logo, a maior contribuição teórica dada pelos estudiosos do OT é a proposta de descentralização de atividades no território, visando a uma maior homogeneização do espaço, enfoque que ainda não era dado às políticas de turismo daquela época (1970), quando o próprio II PND caracterizava e focalizava o litoral brasileiro como único beneficiado para investimentos em turismo e, devido a isso, temos o legado do turismo sol e mar como nosso principal produto turístico até os dias atuais. O que queremos dizer, lembrando a reflexão de Moraes (2005), é que existe uma diferenciação conceitual entre "ordenamento territorial" e "regulamentação do uso do solo", este último conceito sendo muito presente nos planos de turismo na década de 1970.

Segundo Moraes (2005),

O ordenamento territorial diz respeito a uma visão macro do espaço, enfocando grandes conjuntos espaciais (biomas, regiões, redes de cidades etc) e os espaços de interesse estratégico ou usos especiais (unidades de conservação, reservas indígenas, zona de fronteira etc). Trata-se de uma escala de planejamento que aborda o território em seu conjunto, atentando para a densidade de ocupação, as redes instaladas e os sistemas existentes (de transporte, comunicações, energia etc). Interessa-lhes as grandes aglomerações populacionais (com suas demandas e impactos) e os fundos territoriais (com suas potencialidades e vulnerabilidades), numa visão de contiguidade que se sobrepõe a qualquer manifestação pontual do território. (MORAES, 2005, p. 144)

É, pois, essa visão que Moraes (2005) tem de contiguidade territorial que se diferencia da de regulamentação do uso do solo. Essa regulamentação se reduz a normas de caráter jurídico-administrativo para um território específico. Ou seja, mesmo o território sendo pensado como um condicionante importante para o estabelecimento da atividade turística, ainda não era pensado a partir de uma visão macro do espaço que fosse capaz de considerar outros componentes espaciais, como afirma Moraes (idem). E esse entendimento restrito vem sendo deixado à parte no planejamento do turismo, embora sua prática ainda se faça presente.

Passada a década de 1970, o avanço do governo Sarney, em relação à atividade turística, foi legitimar certa liberalização desse mercado (outrora centralizado na EMBRATUR), devido às influências do período de re-democratização do país vivido em seu governo, e o turismo passou a ser 
articulado fortemente com a questão ambiental a partir da Política Nacional de Meio Ambiente, criada no ano de 1981 (BECKER, 2008).

No governo Collor, a Rio-92, uma conferência de nível internacional, que reuniu representantes de diversos países do mundo com o fim de discutirem o desenvolvimento sustentável e os processos de degradação ambiental vivenciados, foi um importante acontecimento que afetou diretamente as reflexões e práticas do turismo no Brasil. Esse evento foi fundamental, pois pressionou a promulgação de uma Política Nacional de Turismo, criada ainda no mesmo ano de 1992 e cujo resultado foi o Plano Nacional de Turismo (PLANTUR), o qual não teve suas propostas efetivadas. Porém, um importante programa, criado neste mesmo ano, foi o PRODETUR, que contemplou inicialmente a região Nordeste (após a revitalização do FUNGETUR).

Com o impeachment de Collor, a gestão de Itamar Franco (1992-1994) criou o Ministério da Indústria, Comércio e Turismo. No último ano dessa gestão, foi criado um importante programa, que subsidiou uma nova proposta de gestão política do turismo em nível nacional: o Programa Nacional de Municipalização do Turismo (PNMT). O PNMT passou a ter suas propostas efetivadas apenas no ano de 1996, perdurando até a última gestão de Fernando Henrique Cardoso (FHC). O programa baseou suas ações na diretriz política de descentralização da gestão do turismo, perpassando por conceitos de gestão democrática e de participação da comunidade. Ou seja, a partir desse programa, o turismo descentralizou-se da gestão nacional, e a EMBRATUR passou a ser responsável por capacitar os municípios para o planejamento dessa nova atividade em suas gestões.

Durante a presidência de FHC (1995-2002), o turismo passou a ser inserido no plano de governo com fortes aspirações neoliberais. O presidente implementou uma nova Política Nacional do Turismo para o primeiro mandato - de 1995 a 1999 - e não houve outra política para o mandato conseguinte (FERNANDES, 2007). Seu principal programa foi o "Avança Brasil" (aliando-se às diretrizes políticas do PNMT). A partir de então, o turismo estabeleceu-se definitivamente como um importante instrumento para o desenvolvimento regional, passando a compor o quadro de planejamento e gestão tanto em escala nacional como em escala estadual e municipal.

Na primeira gestão do presidente Lula (2003/2006), o turismo ganhou um Ministério (MTur - criado em 2003), que deu uma importância significativa ao planejamento do turismo em nível nacional. Sem dúvida, a complexidade da atividade merece prerrogativas políticas que tenham a competência de articular, juntamente com outros ministérios, tais como os dos Transportes, da Defesa, da Integração Nacional, do Meio Ambiente, as ações relacionadas a suas propostas. Logo, no que concerne ao planejamento e à gestão da atividade, as ações de turismo, para as duas gestões de Lula, são respaldadas em dois planos: o PNT - "Plano Nacional do Turismo: diretrizes, metas e programas", de 2003 a 2007; e o PNT - "Plano Nacional do Turismo 2007/2010: uma viagem de inclusão", para o último período de sua gestão presidencial, todos produtos da nova Política Nacional do Turismo implementada pelo governo.

O PNT 2003/2007 é estruturado, segundo Fernandes (2007), a partir de "um diagnóstico de problemas e propõe diretrizes, metas e macroprogramas norteadores do turismo no período indicado" (FERNANDES, 2007, p.45). Seu principal programa foi o Programa de Regionalização do Turismo, cuja importância, inclusive, perdurou no plano da segunda gestão de Lula, o Plano Nacional do Turismo 2007/2010: uma viagem de inclusão.

O PNT 2007/2010 é estruturado, seguindo o modelo do PNT 2003/2006, a partir de um diagnóstico do turismo no país, uma avaliação das ações da gestão anterior do referido presidente e a apresentação das novas metas para o turismo 2007/2010, embasadas agora numa perspectiva de "inclusão". Daremos ênfase ao PNT 20072010, por ser o plano de turismo em vigor em nível nacional e por ser a partir dele que todas as ações locais engendradas no território nacional têm a sua orientação política.

O referido plano é tributário do Programa de Aceleração do Crescimento (PAC) e se respalda na seguinte afirmativa: 
O turismo no Brasil contemplará as diversidades regionais, (...) a criação de emprego e ocupação, a geração e distribuição de renda, a redução das desigualdades sociais e regionais, a promoção da igualdade de oportunidades, o respeito ao meio ambiente, a proteção ao patrimônio histórico e cultural e a geração de divisas (...) (BRASIL - PNT 2007/2010, p. 16)

O plano tem como principais estratégias de ação: o fortalecimento do turismo doméstico, que aborda programas específicos para a inclusão de idosos e pessoas de baixa renda no mercado turístico; a qualificação da mão-de-obra para o turismo, que está voltado para a qualificação profissional e a inclusão de novos postos de trabalho no mercado turístico brasileiro; a criação de um banco de dados nacional com atributos do turismo, para fins de pesquisas científicas e mesmo para subsídio a planejadores. Tal estratégia de ação é de fundamental importância para que os estudos sobre o turismo passem por um processo qualitativo, tornando o Estado capacitado a fornecer referências e dados quantitativos, qualitativos, históricos, dentre outros, sobre o setor. A ausência de tal estratégia de ação prejudica e dificulta sobremaneira os estudiosos que se debruçam sobre a questão do turismo no Brasil.

A descentralização da gestão do turismo tem como objetivo dar continuidade à proposta iniciada na gestão de Itamar Franco pelo PNMT, que tinha suas diretrizes políticas embasadas no compartilhamento da gestão do turismo com a esfera municipal, outrora centralizada nas esferas estadual e nacional. Outra estratégia é a desconcentração do turismo em áreas litorâneas, a qual é muito importante para um novo ordenamento territorial da atividade, visando a implementar o turismo também no interior do país. Essa proposta de desconcentração do setor da área litorânea é um grande avanço no que tange à organização espacial da atividade. Na década de 1970, o turismo, como uma nova estratégia de desenvolvimento regional, estava proposto apenas para o litoral brasileiro, e a necessidade de desconcentração visa a "corrigir" essa diretriz política ora imposta em nosso território.

Apesar de o PNT 2007/2010 não ter um capítulo ou espaço específico para propostas de OT da atividade turística, entendemos a proposta de desconcentração do turismo das áreas litorâneas, bem como a diversificação do produto turístico, que visa à propagação para novos espaços e paisagens, como as principais diretrizes de ordenamento territorial da atividade. Essa proposta contempla a ideia de Estaba (1999) quando diz que é fundamental a redistribuição de oportunidade de expansão de determinados setores no território.

Dentre os vários programas voltados para a execução das estratégias de ação supralistadas, um nos chama particular atenção devido a suas intervenções diretas no que tange ao ordenamento territorial do turismo: trata-se do Macroprograma de Regionalização do Turismo - Roteiros do Brasil (no qual estão inseridos os PRODETURs - Programa Regional de Desenvolvimento do Turismo). É esse o programa direcionador de todas as ações que estão sendo engendradas em nível local no Brasil. Segundo o MTur, é o referido programa, formulado no ano de 2004, que apresenta ao país as propostas de descentralização da gestão da atividade turística bem como as de desconcentração territorial e diversificação do produto turístico, como dissemos há pouco. Dessa forma, visando ao combate da concentração do turismo na área litorânea do Brasil, o programa propõe a desconcentração e a redistribuição de oportunidades para o interior do país, de modo que, por meio de uma coordenação estadual, os municípios possam ser agrupados em "polos" de turismo e possam propor de maneira autônoma seus roteiros e estratégias de implementação a partir de suas diferenciações paisagísticas e características socioculturais.

Outras estratégias que exercem impacto direto na ordenação do território previstas pelo PNT estão inseridas nos macroprogramas de infraestrutura pública, logística e transportes, devido à preocupação com as infraestruturas de apoio ao turismo. Segundo o documento, o turismo, no país, carece de uma infraestrutura de apoio que propicie seu desenvolvimento com qualidade e sustentabilidade, em especial no que se refere à acessibilidade e ao saneamento ambiental. E, para que as intervenções públicas dessa natureza possam ser executadas, é fundamental a articulação entre os órgãos de gestão do turismo e os demais setores da gestão pública, devido aos altos custos 
demandados para a execução. Neste momento, lembramos Pujadas \& Font (1998), quando citam a necessidade de articulação em ações de ordenamento territorial setoriais.

Além de outros órgãos, um programa que será fundamental para a implementação dessas infraestruturas de apoio é o PAC (Programa de Aceleração do Crescimento) e os respectivos PRODETURs, que são:

- Programa de Ação Para o Desenvolvimento do Turismo do Nordeste do Brasil (PRODETUR $\mathrm{NE}$;

- Programa de Ação Para o Desenvolvimento do Turismo no Sul do Brasil (PRODETUR SUL);

- Programa de Ação Para o Desenvolvimento do Turismo no Norte do Brasil (PROECOTUR ou PRODETUR NORTE); e

- Programa de Ação Para o Desenvolvimento do Turismo no Centro e Sudeste do Brasil (PRODETUR JK).

É possível perceber que, baseando-se no modelo de descentralização da gestão do turismo proposto pelo PNT, as obras de incidência direta no território são, basicamente, sistematizadas nos planos regionais de turismo, deixando-se sob a responsabilidade dos governos estaduais e municipais a análise das principais carências e ações de que a localidade necessita para o desenvolvimento da atividade. Ou seja, a gestão nacional do turismo traça apenas as diretrizes políticas para os planos regionais, não definindo sistematicamente diretrizes de ordenamento territorial para os planos das regiões com seus respectivos polos, e essa ausência de um planejamento integrado de base espacial, que se repete também nos planos regionais, faz com que a atividade corra o risco de fomentar a desagregação territorial.

Outra discussão que tangencia a questão do ordenamento territorial do turismo no Brasil e questiona a proposta de interiorização e diversificação do PNT é a constante necessidade de qualificação dos espaços onde o turismo já se consolidou. Ou seja, por mais que seja latente a necessidade de interiorizar o turismo, faz-se necessário também que as áreas onde a atividade já se tenha estabelecido contenham infraestrutura básica e toda a logística necessária para dar suporte ao setor. Sem dúvida, esse é outro grande desafio para a gestão pública em turismo no país.

Talvez essas discussões sobre uma proposta de ordenação territorial para o turismo, bem como o melhoramento de base para as áreas já turistificadas, sejam apenas o reflexo da carência de uma legislação que tenha implicações no ordenamento e na fiscalização do setor, ferramenta essa de suma importância para o controle da qualidade dos serviços turísticos e para a melhoria da vida da população. Essa reflexão sugere outra questão, relacionada a um problema de suma importância que compromete o estabelecimento do turismo como uma atividade econômica e socialmente viável: é a fragilidade institucional da gestão do turismo vivenciada em todo o Brasil. É sob uma imensa fragilidade institucional que as ações locais se realizam, fazendo, muitas vezes, com que as propostas para a qualificação do setor não sejam executadas.

Com essas reflexões, queremos chamar a discussão suscitada por Steinberger (2006) quando analisa a perda da importância do Estado, do planejamento e das políticas públicas nacionais como consequência do neoliberalismo. Segundo a autora, essa "fragilidade federal" pós-ditadura fez com que se permitisse a invasão de qualquer tipo de novidade, transformando o território brasileiro em um laboratório de experiências pontuais em que a interferência de atores hegemônicos e de consultorias capitalistas ajudam a deixar de se pensar num projeto de nação pelo viés da descentralização. Nesse contexto de desagregação institucional, descentralização política e exacerbada autonomia local, vemos ações de caráter integrativo, como ações de ordenamento territorial, sendo comumente confundidas com políticas territoriais independentes e sem coesão. 
Lembramos também da reflexão supracitada a partir de Steinberger (2006) quando percebemos que o PNT 2007/2010 repassa para o macroprograma de regionalização do turismo seu referencial territorial. Isso significa que, como o referido macroprograma é planejado e executado em escala local, a responsabilidade do OT é repassada para gestões locais, deixando-se a cargo dessas gestões, através dos PRODETURs, os estudos, diagnósticos e intervenções que irão reestruturar de fato o território, mesmo carecendo de referenciais de ordenamento territorial sistematizados para a atividade.

Preocupados com essa questão, fomos levados a investigar como o planejamento do turismo em nível local contempla as ações de ordenamento territorial para a atividade, dando como exemplo o estado do RN.

\section{ORGANIZAÇÃO DAS POLÍTICAS PÚBLICAS DE TURISMO NO BRASIL: A ESCALA LOCAL}

Quando alteramos a nossa escala e damos um enfoque local em nosso estudo, deparamo-nos com problemas de gestão ainda não superados no que diz respeito ao planejamento em turismo. A referida realidade é constatada quando tomamos o estado do Rio Grande do Norte como exemplo e todas as fragilidades, no que concerne à gestão do turismo, vêm à mostra.

Diferentemente do planejamento turístico a nível nacional, o Rio Grande do Norte, reconhecido estado turístico nacional e internacionalmente, não tem um plano de turismo que contemple sistematicamente todas as ações engendradas no seu território. As ações engendradas, até então, são voltadas para a divisão do estado em polos de turismo - de acordo com a proposta do Macroprograma de Regionalização do Turismo (PNT 2007/2010) - e ações específicas para cada polo (figura 1).

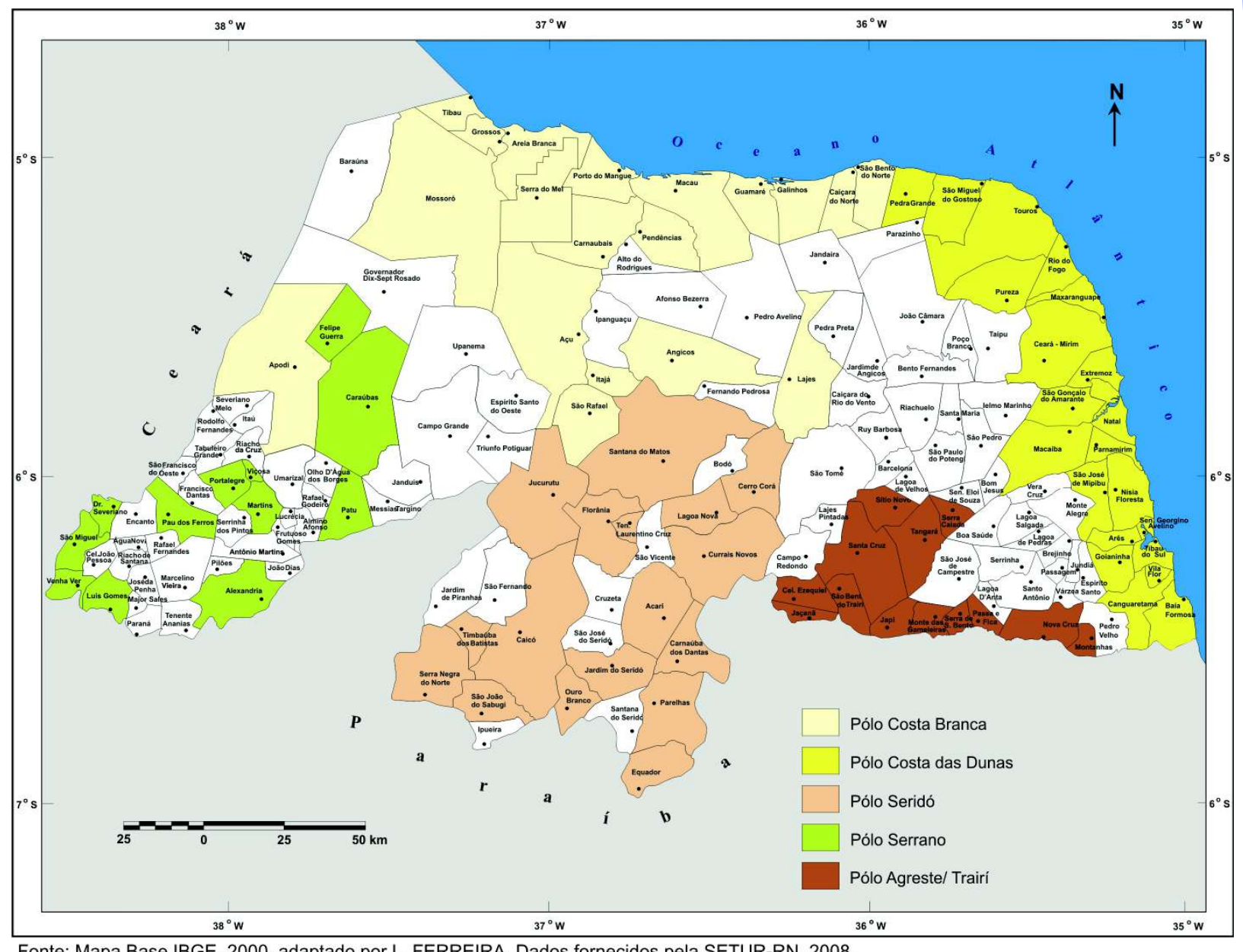

Fonte: Mapa Base IBGE, 2000, adaptado por L. FERREIRA. Dados fornecidos pela SETUR-RN, 2008.

Figura 1 - Estado do Rio Grande do Norte a partir da divisão dos Polos Turísticos 
De acordo com as diretrizes do PRODETUR NE (Macroprograma de Regionalização do Turismo, PNT 2007/2010), cada polo de turismo deve ter um Plano de Desenvolvimento Integrado do Turismo Sustentável (PDITS). Contudo, dos cinco polos de turismo que o estado definiu, apenas o Costa das Dunas contém o seu plano.

Ou seja, a partir da figura 1, percebemos que dos 167 municípios que atualmente compõem o estado do Rio Grande do Norte, 82 deles estão inseridos nas propostas de roteiros turísticos organizados em polos. A criação dos polos segue uma das principais diretrizes políticas propostas no PNT 2007/2010 que é o tripé interiorização, desconcentração e diversificação dos produtos turísticos de estados e municípios, fazendo com que, de acordo com o modelo de descentralização da gestão (outra importante diretriz política do PNT), os estados e municípios fiquem a cargo de criarem seus planos e de formularem suas propostas de turismo, a partir do agrupamento de municípios com características culturais, paisagísticas e geomorfológicas semelhantes.

Assim, pelo fato de o PDITS do polo Costa das Dunas ser atualmente o único plano sistematizado dentre as demais propostas de polos turísticos do estado do Rio Grande do Norte, demonstra que, embora a desconcentração do turismo de áreas litorâneas seja uma das principais metas do PNT 2007/2010, o PRODETUR II começa novamente a execução de suas obras a partir do litoral, e paulatinamente construir os planos de desenvolvimento do turismo sustentável (PDITS) para os outros polos do interior do estado. Desta forma, uma das principais diretrizes territoriais do PNT - baseada no tripé interiorização, desconcentração e diversificação do produto turístico no Brasil - ainda é prospectiva, percebendo que a atividade se organizou e se re-organiza atualmente no estado do RN mais uma vez pelo litoral, priorizando polos e municípios turísticos e propiciando a concentração, diferenciação e fraturas territoriais.

O PRODETUR - fase I foi de fundamental importância para a reestruturação do território dos municípios onde foi implementado. Nesse novo momento, o programa tem por objetivo, segundo o PDITS-Costa das Dunas, dar continuidade às ações e aos projetos desenvolvidos em sua fase anterior de forma a "proporcionar a melhoria da qualidade de vida da população fixa nas áreas beneficiadas, viabilizando seu acesso aos serviços urbanos e aos postos de trabalho, possibilitando a melhoria das condições ambientais e garantindo segurança aos investidores" (PDITS-Costa das Dunas).

O PDITS-Costa das Dunas é um produto técnico que foi desenvolvido pela empresa Technum Consultoria LTDA, sob a coordenação da SETUR-RN. Estiveram envolvidos no processo de elaboração o governo do estado, prefeituras municipais, a iniciativa privada, o terceiro setor, o Ministério do Turismo, o BID e o BNB. Além de participar da elaboração do plano, a grande maioria desses órgãos compõe o Conselho de Turismo do polo Costa das Dunas, formado por:

- Governo federal: BNB, BB, CEF, BNDS, PETROBRAS, Patrimônio da União - Regência Regional, FUNASA e INFRAERO-RN;

- Governo Estadual: SEPLAN, SIN, SEJUC, SETUR, SESED, SEEC, IDEMA e Agência de Fomento do RN;

Governo municipal: Prefeituras dos municípios de Baía Formosa, Canguaretama, Tibau do Sul, Senador Georgino Avelino, Nísia Floresta, Parnamirim, Natal, Extremoz, Ceará-Mirim, Rio do Fogo, Maxaranguape, São Miguel do Gostoso, Touros e Pedra Grande;

. Terceiro setor: UFRN, UNP e CEFET-RN;

Setor Privado: Federações do Comércio, das Indústrias, da Agricultura do RN, Federação das Empresas de Transportes e Passageiros do Nordeste e SEBRAE.

Assim, o PRODETUR - fase II, segundo o plano, vem com a proposta de "consolidar, completar 
e complementar" o turismo na região. Ou seja, busca consolidar o que já foi realizado na primeira etapa do programa; completar as ações que não foram finalizadas ou executadas nos municípios, mas que continuam sendo necessárias à sustentabilidade da atividade turística no polo; e complementar aquelas ações identificadas como prioritárias. Para tanto, além dos municípios já contemplados na primeira etapa do programa (Natal, Ceará-Mirim, Parnamirim, Extremoz, Nísia Floresta e Tibau do Sul), acrescentaram-se no plano os municípios de Arês, São Gonçalo do Amarante e Senador Georgino Avelino. Porém, é valido destacar que os municípios contemplados no PDITS-Costa das Dunas não são todos que realmente compõem o polo (figura 2), fragmentando a região e privilegiando municípios em detrimento de outros. Ou seja, a fragilidade institucional local faz com que as diretrizes do turismo previstas no plano nacional da atividade não contemplem, muitas vezes, suas propostas de integração social, entrada de divisas e que seja um vetor para a diminuição das diferenciações regionais.

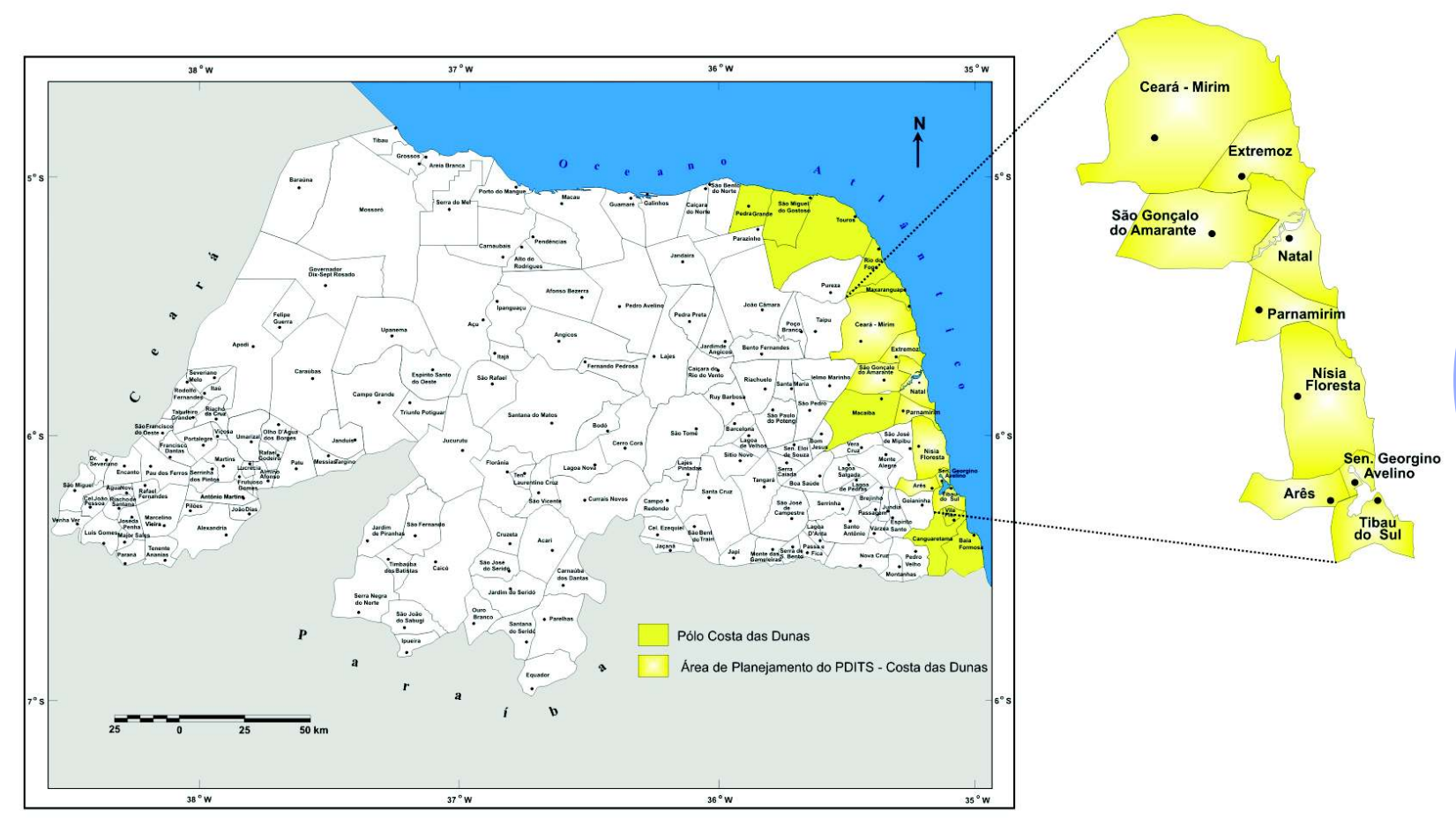

Fonte: Mapa Base IBGE, 2000, adaptado por L. FERREIRA, 2008. Dados fornecidos pela SETUR-RN.

Figura 2 - Municípios componentes da área de planejamento do PDITS-Costa das Dunas

\section{CONSIDERAÇÕES FINAIS}

Com uma hierarquia esquemática das políticas públicas de turismo, partindo da escala nacional para a local, tem-se o seguinte quadro (figura 3) da organização das políticas públicas de turismo no Brasil para o estado do RN.

Devemos considerar a grande dificuldade de encontrar dados referentes ao turismo, principalmente quando se trabalha na esfera do planejamento e da gestão desta atividade. É evidente a carência de informações básicas sobre o setor nos seus respectivos órgãos públicos. O PNT 2007/2010 expressa a necessidade latente de se organizar, em nível nacional, por meio da tecnologia da informação, um banco de dados com indicadores correlatos ao setor, para que se possa garantir, com uma maior clareza, a magnitude (ou não) da atividade turística no contexto nacional.

Alguns avanços positivos e qualitativos vêm ocorrendo, ao longo dos anos, como, por exemplo, o próprio PNT 2007/2010, que, embora ainda não contenha uma política nacional de ordenamento 
territorial para o turismo, é um documento que mostra de forma inteligente e articulada como se deve pensar o turismo no contexto nacional.

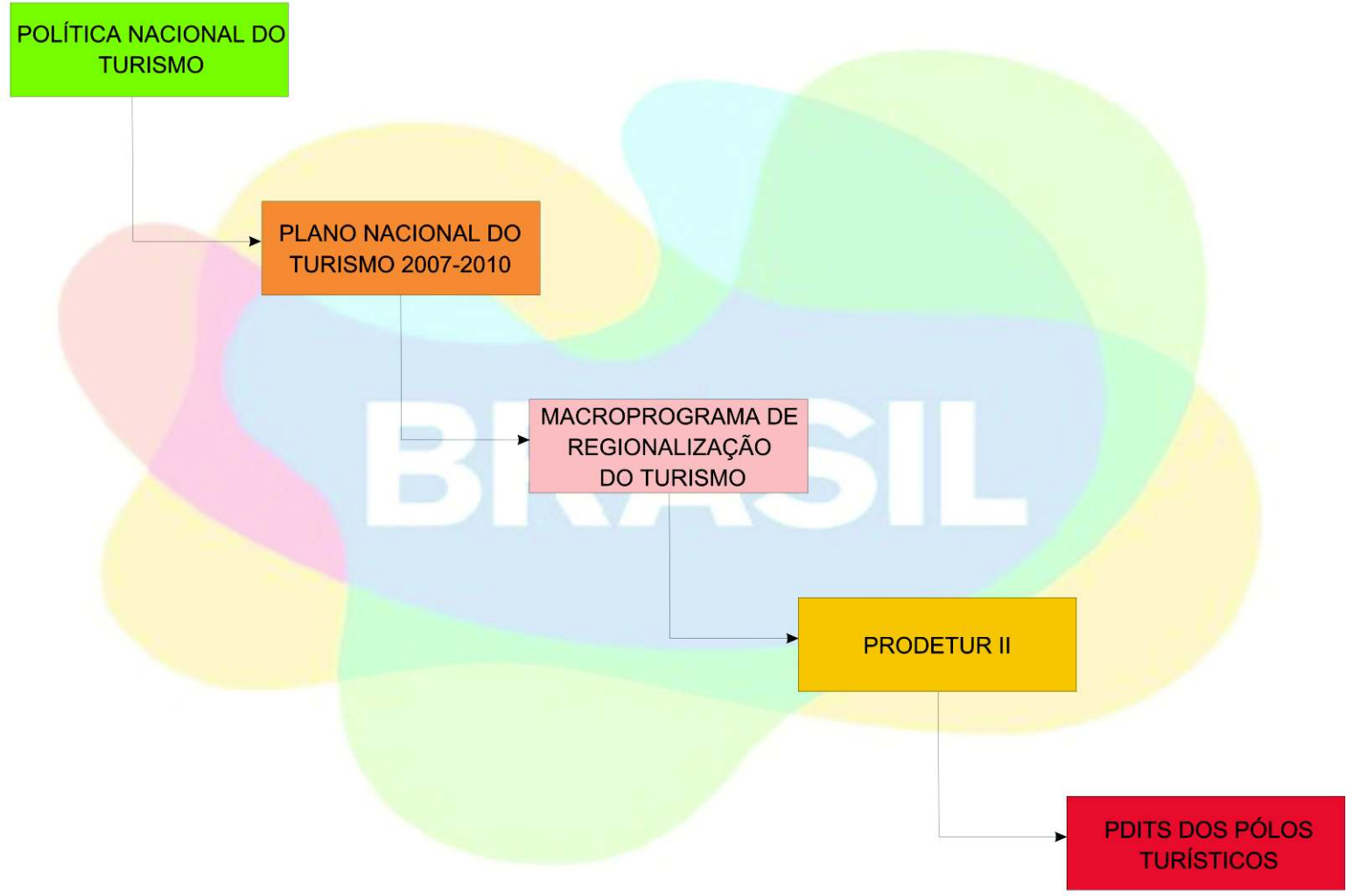

Figura 3 - Organograma da estrutura das políticas públicas de turismo no Brasil

O plano identifica as grandes lacunas existentes no turismo do Brasil, que são dificuldades enfrentadas tanto pelos planejadores quanto pelos pesquisadores, e aponta diretrizes gerais que devem ser encaminhadas pelos estados e municípios, através do modelo de descentralização que herdamos do Programa Nacional de Municipalização do Turismo (PNMT), em meados da década de 1990. Todavia, não podemos deixar de afirmar que foi naquele momento que a grande desarticulação em relação ao planejamento e à gestão da atividade turística se iniciou, e ainda hoje os órgãos de turismo estaduais e municipais do Brasil são de uma fragilidade institucional não questionável.

Foi devido a isso, então, que este artigo analisou as políticas nacionais e locais de turismo. Cabe ressaltar que o local deve ser entendido aqui como a esfera estadual, a qual, apesar de todas as dificuldades, ainda pôde fornecer-nos informações a respeito das políticas que estão sendo realizadas no contexto do estado do Rio Grande do Norte, visto que compõem demandas nacionais com prazos, deveres e orçamentos públicos a serem cumpridos. Não foi analisada a escala municipal, sobretudo pela inexistência de qualquer política ou plano de turismo para a gestão em vigor, por mais simples e objetivos que fossem. Essa realidade foi encontrada em todos os municípios do polo Costa das Dunas, os quais dispõem de secretaria de turismo, inclusive na capital, Natal, dinamizadora da atividade.

Além do mais, este artigo traz uma importante contribuição diante da ausência de estudos específicos para o ordenamento territorial da atividade que analise o espaço a partir de uma visão macro, uma vez que o turismo, na contemporaneidade, ser importante agente de desagregação e de fraturas territoriais 


\section{REFERÊNCIAS BIBLIOGRÁFICAS}

BECKER, B. Políticas e Planejamento do Turismo no Brasil. In: YÁZIGI, E.; CARLOS, A. F. A.; CRUZ, R. de C. A. Turismo: espaço, paisagem e cultura. São Paulo: HUCITEC, 1996.

BECKER, B. Políticas e planejamento do turismo no Brasil. Disponível em $<$ http://www.ivt.coppe.ufrj. br/caderno/ojs/viewarticle.php?id=3> Acesso em 05.11.2008 às $11 \mathrm{~h}$.

BONALD, O. Planejamento e organização do turismo. Recife/ PE: EMPETUR, 1978.

BRASIL - MINISTÉRIO DO TURISMO. Plano Nacional do Turismo: diretrizes, metas e programas 2003/2006. Brasília, 2003.

BRASIL - MINISTÉRIO DO TURISMO. Plano Nacional do Turismo 2007/2010: uma viagem de inclusão. Brasília: MTur, 2006.

BRASIL - MINISTÉRIO DO TURISMO. Programa de Regionalização do Turismo - Roteiros do Brasil, Diretrizes Políticas, 2004.

BRASIL. Projeto do II Plano Nacional de Desenvolvimento - II PND (1975-1979). Brasília/DF: Senado, 1974.

ESTABA, R.M. La descentralización y la ordenación del territorio de Venezuela: estratégias hacia la modernidad. Scripta Nova. Revista eletrônica de geografia y ciencias sociales, Universidad de Barcelona, núm. 54, 15 de diciembre de 1999. Disponível em <http://www.ub.es/geocrit/sn-54.htm> Acesso em 07.11.2008 às $01: 30 \mathrm{~h}$.

FERNANDES, S.W.R. A inserção do espaço geográfico no planejamento nacional do turismo. Brasília: Instituto de Ciências Humanas, Departamento de Geografia: UnB, 2007.

MORAES, A. C.R. Meio ambiente e ciências humanas. São Paulo: Annablume, 2005.

PLANO DE DESENVOLVIMENTO INTEGRADO DO TURISMO SUSTENTÁVEL DO POLO COSTA

DAS DUNAS - PDITS-Costa das Dunas. Documento disponível na sede do PRODETUR em Natal/ RN, 2008.

PUJADAS, R. FONT, J. Ordenación y planificación territorial. Madrid: España: Sintesis, 1998.

STEINBERGER, M. Território, Ambiente e Políticas Públicas Espaciais. In: STEINBERGER, M. (Org.). Território, ambiente e políticas públicas espaciais. Brasília: Paralelo 15 e LGE, 2006. v. 1. 406 p.

Trabalho enviado em fevereiro de 2011 Trabalho aceito em maio de 2011 